\title{
Application of ant colony optimization for reconfiguration of shipboard power system
}

\author{
Sri Hari Krishna Vuppalapati ${ }^{1}$, Anurag K. Srivastava ${ }^{2 *}$ \\ ${ }^{1}$ Department of Electrical Engineering, Indian Institute of Technology Kharagpur, INDIA 721302 \\ $2^{2 *}$ Department of Electrical and Computer Engineering, Mississippi State University, Mississippi State, MS, USA 39762 \\ "Corresponding Author: e-mail:srivastava@ece.msstate.edu, anurags@ieee.org
}

\begin{abstract}
The shipboard power system (SPS) supplies energy to sophisticated systems of weapons, navigation, services and communication. Due to battle damage or faults, electric energy delivery may be interrupted to critical loads. Reconfiguration of electrical network in the SPS is necessary, to either restore the service to all the possible loads or to meet some of the operational requirements of the naval ship. In this research work, ant colony optimization (ACO) has been utilized to reconfigure given SPS network, satisfying the operational requirements, priorities of the loads and considering islanding operation and distributed generation. Graph theory has been applied to represent SPS electrical network to simplify the mathematical formulation to be used by ACO. Developed technique has been applied to an eight bus and thirteen bus representative shipboard power system model to reconfigure, while maximizing the load magnitude, or load priority, or load magnitude with priority. Satisfactory results have been obtained for both the test cases.
\end{abstract}

Keywords: Shipboard power systems, islanding, reconfiguration, graph theory, ant colony algorithm

\section{Introduction}

Reconfiguration of an electrical network in shipboard power systems (SPS) is an important task to maximize the survivability, security and reliability of naval ships (Jayabalan et al, 2005). The protection schemes in SPS only provide fault detection and isolation functions, but do not consider system stability or power balance after the fault isolation. When a fault occurs, the fault should be isolated immediately, which may result in un-faulted sections to be left without supply. It is required to quickly reconfigure to restore supply to these un-faulted sections to increase the system survivability. Reconfiguration refers to the ability of the system to redirect power by closing or opening of breakers to the loads in the event of a component failure, fault or generator loss (Davey et al, 2005). Reconfiguration also allows power to be quickly diverted to high power applications/ devices for very small time frames, which is vital for next generation, high-power weapons.

In SPS, generators are connected in ring configuration through generator switchboards. Bus tie circuit breakers interconnect generator switchboards to allow the transfer of power from one to another. Load centers and some individual loads are supplied from generator switchboards. Reconfiguration approach for SPS has been address in several literatures in the past. The reconfiguration problem for shipboard power systems has been addressed using the heuristic-search approach in (Butler et al 2000). This method is very simple but has problems in restoration with an increasing number of loads. In the method of network flow approach (Butler et al, 1999; 2001), the load priorities have not been considered. Authors have provided comparison of several techniques for reconfigurations of distribution system in (Yu et al, 2008; Meek et al, 2004; Xiuxia et al, 2006; Kleppinger et al, 2010). A hybrid approach for reconfiguration has been discussed in (Ahuja et al, 2007). Particle swarm based reconfiguration for shipboard power system has been presented in (Kumar et al, 2007). Reconfiguraion using genetic algorithm for SPS have been discussed in (Padamati et al, 2007; Luan et al, 2002; Pendurthi et al, 2009). Ant colony based reconfiguration for distribution system has been presented in (Daniel et al, 2005) and multi agent based in (Huang et al, 2009). While several methods exist for terrestrial distribution system, not many techniques exist in literature for reconfiguration of shipboard power system with all the practical constraints including consideration of islanding or consideration of load priority. 
In this paper, a reconfiguration methodology, using an ant colony optimization algorithm is presented that will find post-fault optimal configuration meeting designated objectives and system constraints. Graph theory is used to represent the power system model. As long as a power network is represented with a graph, the corresponding graph matrices based on the graph adjacency and incidence structures can describe the system topology (Huang, 2006). The matrix specification provides far more efficient ways of representing a larger or more complicated graph than a pictorial representation. The optimization algorithms are then applied for power supply restoration and optimal load shedding. The remaining part of the paper is organized as follows. Section 2 describes the graph representation of SPS. Section 3 presents the mathematical problem formulation for reconfiguration. The ant colony algorithms and developed reconfiguration techniques are described in section 4. Section 5 presents the results for different fault scenarios applied to eight and 13 bus SPS. Finally, section 6 concludes the paper.

\section{Graph Representation of Shipboard Power System}

Consider a simple SPS model as shown in figure 1. This system consists of four generators and six loads. Graphical representation of system is shown in figure 2. In a bus arranged power system, the main components include service switchboards, buses, cables, generators, and load feeders. These components are interconnected by breakers. Table 1 shows the relationship between the major components of Shipboard Power System (SPS) and the corresponding graphical elements.

Table 1. Graph Representation of Shipboard Power System Model

\begin{tabular}{|c|c|}
\hline Components In Power System & Elements In Graph \\
\hline Generator, Bus bar, Cable, Load & Vertex \\
\hline Circuit Breaker & Edge \\
\hline
\end{tabular}

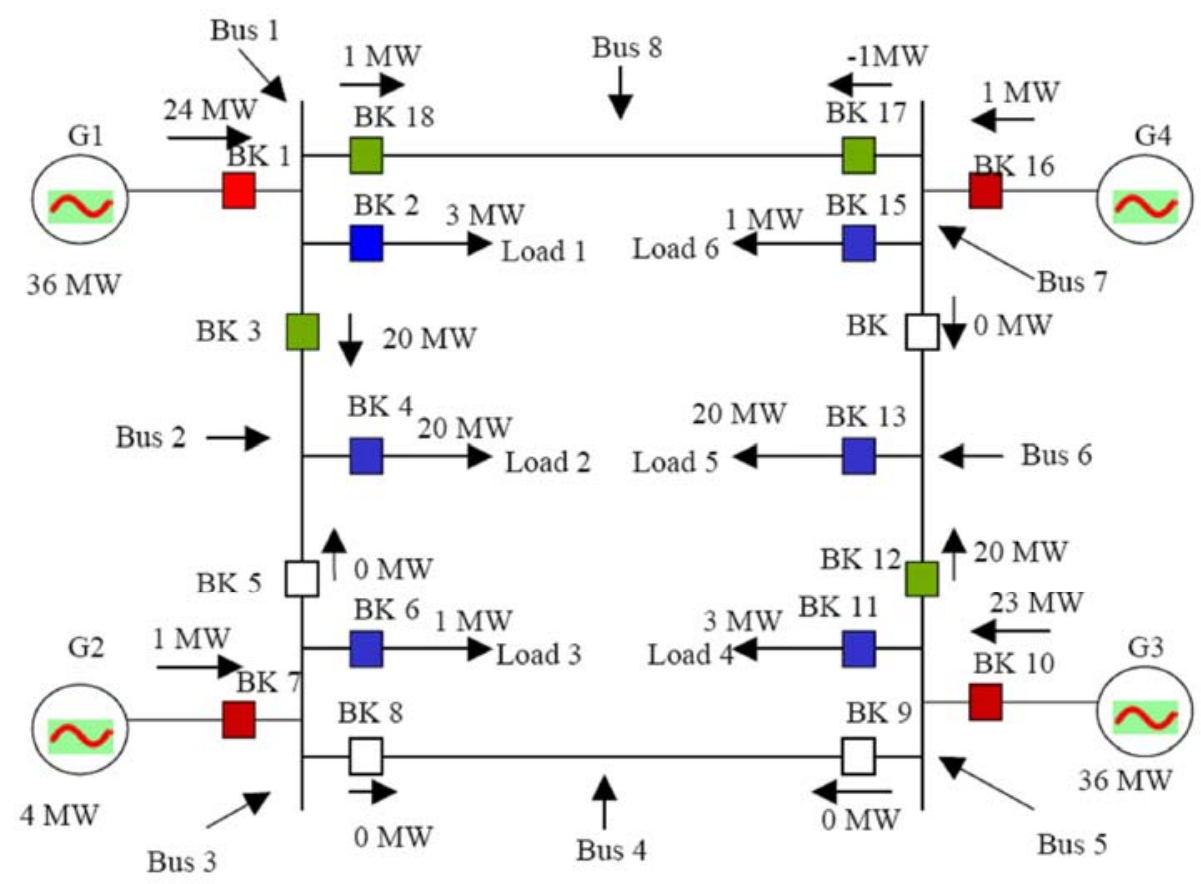

Figure 1. A shipboard power system model

Figure 1 shows a SPS model, which consists of six bus switchboards (bus 1, bus2, bus 3, bus 5, bus 6 and bus 7), two cables (bus 4 and bus 8), four generators (G1, G2, G3, and G4), and eighteen breakers (with current transformer). Figure 2 shows the graph representation of the power system model in figure 1. The direction of the edge is related to the direction of flow of power through the breaker. The power system is divided into different zones. Each bus with directly connected breakers is defined as a zone in the protection scheme. In the corresponding system of graph representation, each vertex with the directly connected edges represents a protection zone (Huang, 2006).

After simplifying a power system topology into a graph, the corresponding matrices can represent the graph mathematically for computer implementation. This matrix S(ZoneI) is called breaker-to-zone matrix or edge-to-vertex (EtoV) matrix. For the power system shown in figure 1 the incidence vectors of the matrix EtoV are shown in table 2. The EtoV matrix is an 8x18 matrix 
corresponding to eight zones and eighteen breakers. The positive sign represents the flow of power towards a zone and negative sign represents flow of power away from the zone.

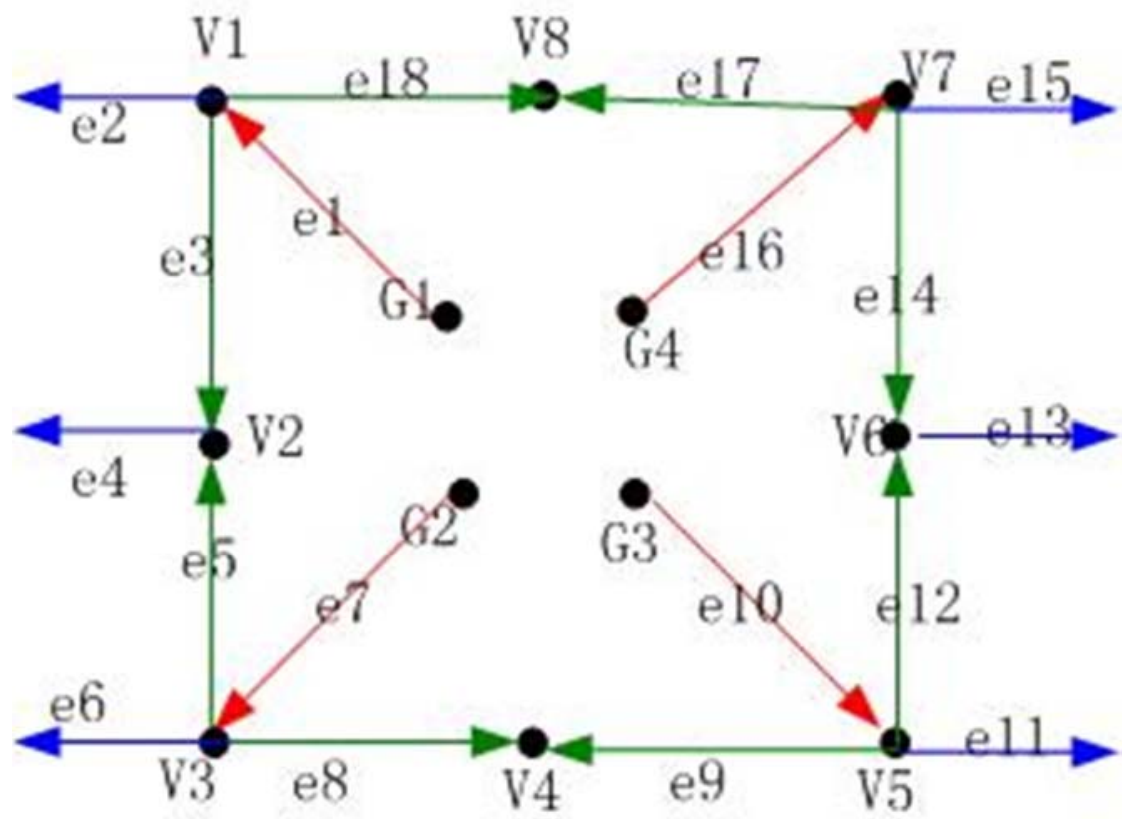

Figure 2. Graph representation of shipboard power system model

Table 2. Input data for Reconfiguration Algorithm

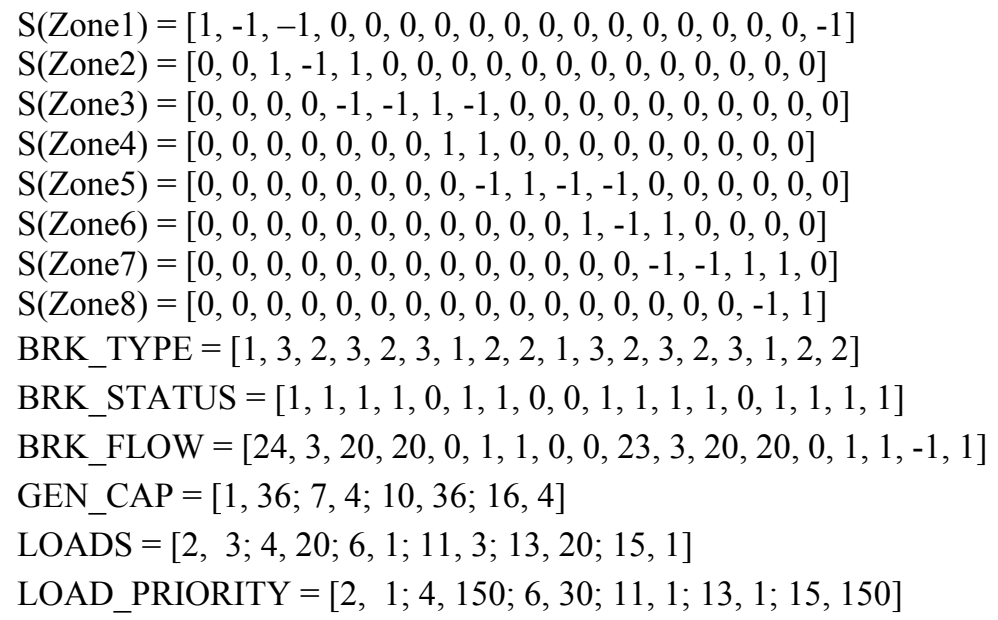

Additional data required for the system include the breaker type (BRK_TYPE), breaker status (BRK_STATUS), breaker flow (BRK_FLOW), generator capacity (GEN_CAP), loads and load priority as shown in table 2 . There are three types of breaker: ' 1 ' refers to the generator breaker, which connects a generator with a zone, ' 2 ' refers to the load breaker, which connects a load feeder with a zone, and ' 3 ' refers to the tie breaker, which connects two zones.

The breaker status matrix represents the system breaker open/close status. A " 1 " means that the breaker is closed (ON), and a " 0 " means that the breaker is open (OFF). The instantaneous power flow through each breaker can be obtained from the power flow. The generator capacity (GEN_CAP) matrix is a two-column matrix. The first column contains the index of the generator breaker and the second column contains the corresponding generator capacity. The instantaneous power flow (BRK_FLOW) matrix and generator capacity matrix are also shown in table 2 with the unit of MW. The load priority (LOAD_PRIORITY) matrix is another important piece of information for reconfiguration with possible load shedding. In the load priority matrix shown in table 2 , the first column contains the index of the breaker; the second column contains the load priority, with larger numbers indicating the higher priority. In the eight bus power system model shown in figure 1, loads 2, 3, and 6 have higher priority than loads 1, 4 and 5 . 


\section{Problem Formulation}

The problem statement can include objectives such as minimization of power loss, maximum power delivery to the loads, and maximum power delivery to a single load. The objective function considered here is to maximize the power supply to unaffected loads and supply power to high priority loads through load shedding, if necessary. The loads are classified as non-vital, semi-vital and vital loads. These loads are multiplied by a given weighting factor $P_{i}$. The weighting factor is selected so that the vital and semi-vital load contributions are greater than the largest non-vital load contribution in objective function. The objective function to maximize the load magnitude is defined as follows,

Maximize $L_{1}+L_{2}+L_{3}+\ldots+L_{n}$

Subject to $P_{\text {gen }} \geq P_{\text {load }}$

The objective function for maximization of load with given priority includes two objectives with different weighting factors. These weighting factors are selected depending on the situation whether to restore the loads by considering load priority or without considering load priority. The magnitude of the objective function depends on switch configuration $X$. The objective function as given in (Kumar et al, 2007; Padamati et al, 2007) and defined as equation (1),

$F=W_{M}\left[x(1) L_{1}+x(2) L_{2}+\cdots+x(n) L_{n}\right]+W_{P}\left[P_{1} x(1) L_{1}+P_{2} x(2) L_{2}+\cdots+P_{n} x(n) L_{n}\right]$

Where,

' $x$ ' is the switch configuration.

$x(i)=1$ indicates breaker closed for $\mathrm{i}=1,2, \ldots, \mathrm{n}$.

$x(\mathrm{i})=0$ indicates breaker open for $\mathrm{i}=1,2, \ldots, \mathrm{n}$.

$L_{1}, L_{2}, L_{3}, \ldots, L_{n}$ are load values.

$P 1, P 2, P 3, \ldots, P n$ are priorities of loads.

$W_{M}$ is weighting factor for load selection by considering load magnitude.

$W_{P}$ is weighting factor for load selection with considering load priority.

\section{Ant Colony Algorithms for Reconfiguration}

4.1 Ant colony discrete algorithm: The ant colony algorithm is a probabilistic technique for solving computational problems and was first proposed by Marco Dorigo in 1992. The procedure can be applied irrespective of the objective function complexity in most of the cases, making it useful for functions that are highly nonlinear. The first algorithm was aiming to search for an optimal path in a graph, based on the behavior of ants seeking a path between colony and food.

Initially ants wander randomly and upon finding food they return to their colony while laying down pheromone trails. The pheromone level evaporates with time, so that other ants can reach the food by following the "shortest" paths marked with strongest pheromone quantities. A shortest path by comparison, gets marched over faster, and thus the pheromone density remains high as it is laid on the path as fast as it can evaporate. An Ant tends to choose a path positively correlated to the pheromone intensity of founded trails. If there were no evaporation at all, the paths chosen by first ants would be excessively attractive to the following ones.

The discrete algorithm is a constructive meta-heuristic for the travelling salesman problem (Dorigo et al, 1997) based on this biological metaphor. It associates an amount of pheromone $\tau(i, j)$ with the connection between two cities. Each ant is placed on a random start city, and builds a solution going from city to city, until it has visited all cities. The probability that an ant $\mathrm{k}$ in a city $\mathrm{i}$ choose to go to a city $\mathrm{j}$ is given by equation (2):

$$
P_{i j}^{k}= \begin{cases}\tau_{i j}[(t)]^{\alpha}\left[\eta_{i j}(t)\right]^{\beta} / \sum_{p \in \text { allowed } k(t)}\left[\tau_{i p}(t)\right]^{\alpha}\left[\eta_{i p}(t)\right]^{\beta} & \text { if } j \in \operatorname{allowed~} k(t) \\ 0 & \text { Otherwise }\end{cases}
$$

\section{Otherwise}


In this equation, $\tau(i, j)$ is the pheromone between $i$ and $j$ and $\eta(i, j)$ is a simple heuristic function and this is the inverse of the cost of the connection between $i$ and $j$. It is the parameter $\beta$ which defines the relative importance of the heuristic information as opposed to the pheromone evaporation. Once all ants have built a tour, the pheromone trail intensity will be updated. This is done according to following equations.

$$
\tau_{i j}(t+n)=(1-\rho) \tau_{i j}(t)+\Delta \tau_{i j}(t, t+n)
$$

The left part of the equation makes the pheromone on all edges decay where as the right part of the equation increases the pheromone level on all edges visited by all ants. The amount of pheromone an ant $\mathrm{k}$ deposits on an edge is defined by:

$$
\Delta \tau_{i j}^{k}(t+n)= \begin{cases}Q / L_{k} & \text { if ant k uses edge }(\mathrm{i}, \mathrm{j}) \text { in its tour } \\ 0 & \text { Otherwise }\end{cases}
$$

$\mathrm{L}_{\mathrm{k}}$ is the length of a tour created by ant $\mathrm{k}$. In this way, the increase of pheromone of an edge depends on the number of ants that use this edge. More details on ant colony algorithm have been provided in (Dorigo et al, 2004). The power system optimization problems are dealt with discrete ant colony optimization in (Daniel et al, 2005 and Hamdaoui et al, 2008). Problem addressed in this paper is unique due to possible load shedding requirement and the output being a binary value.

4.2 Modified ant colony optimization-I: The discrete algorithm is ordering problem such as traveling salesman problem or quadratic assignment problem as discussed before. But subset problems are quite different from ordering problems. We need to select the best subset out of the whole set, possibly satisfying some additional constraints. There is no concept of path here, so it is difficult to apply the concepts developed in discrete ant colony algorithm in subsection 4.1. For the ordering problems solution is fixed length, as we have to search for a permutation of a known number of elements. Solutions for subset problems do not have a fixed length. Thus it is necessary to establish a number, $\mathrm{N}_{\max }$, which will be used to determine the end of construction cycle for all the ants (Leiguizamon et al, 1999). Here are the procedural steps:

- The intensity of a pheromone trail on item $i$ at time $t+N_{\max }$ is given by following equation, where $\mathrm{N}_{\max }<\mathrm{n}$ is the maximum of items allowed to be added to some solution by some ant.

$$
\tau_{i}\left(t+N_{\max }\right)=(1-\rho) \tau_{i}(t)+\Delta \tau_{i}^{k}\left(t, t+N_{\max }\right)
$$

- The increment in the pheromone level in the time $\mathrm{t}+\mathrm{Nmax}$ is given by summing the contribution of each ant. In the function $G$ depends on the problem and gives the amount of trail being added to item i. Usually $G\left(L_{k}\right)=Q / L_{k}$ or $G$ $\left(\mathrm{L}_{\mathrm{k}}\right)=\mathrm{QL}_{\mathrm{k}}$ for minimization or maximization problems and $\mathrm{Q}$ is a parameter of the method. $\mathrm{L}_{\mathrm{k}}$ is the objective or fitness function found by $\mathrm{k}^{\text {th }}$ ant .

$$
\begin{aligned}
& \Delta \tau_{i}\left(t, t+N_{\max }\right)=\sum_{i=1}^{n} \Delta \tau_{i}^{k}\left(t, t+N_{\max }\right) \\
& \Delta \tau_{i}^{k}\left(t, t+N_{\text {max }}\right)= \begin{cases}\mathrm{G}\left(L_{k}\right) & \text { if ant k incorporates item i } \\
0 & \text { Othewise }\end{cases}
\end{aligned}
$$

- The probability of selecting a particular item ip as the next item is given by following equation, where allowed $\mathrm{k}(\mathrm{t})$ is the set of remaining feasible items. Thus, the higher value of $\tau_{\text {ip }}$ and/or $\eta_{\text {ip }}$ the more profitable to include item ip in the partial solution. 


$$
\mathrm{P}_{\mathrm{ip}}^{\mathrm{k}}(t)= \begin{cases}\tau_{\mathrm{ip}}[(\mathrm{t})]^{\alpha}\left[\eta_{\mathrm{ip}}(\mathrm{t})\right]^{\beta} / \sum_{\text {ip } \in \text { allowed } \mathrm{k}(\mathrm{t})}\left[\tau_{\mathrm{j}}(\mathrm{t})\right]^{\alpha}\left[\eta_{\mathrm{j}}(\mathrm{t})\right]^{\beta} & \text { if ip } \in \operatorname{allowed~} \mathrm{k}(\mathrm{t}) \\ 0 & \text { Otherwise }\end{cases}
$$

- We consider two types of heuristics, static and dynamic.

Static: It is set at the beginning of run to a fixed value.

Dynamic: It depends on the partial solution.

The subset-based and ordering-based algorithms have many features in common. However, in the ordering based, the pheromone is laid on the paths while for subset problems no path exists connecting the items. In the ordering problem "the more amount of trail on a particular path, the more profitable is that path". This idea was adapted here in the following way: "the more pheromone trail on a particular item, the more profitable that item is". In other words we move the pheromone from paths to items. At the same time, a local heuristic is also used in the new version, considering items only instead of connections between them.

4.3 Modified ant colony optimization-2: In this algorithm, the variable selection is the main criteria. There is no concept of path here, so it is difficult to apply the discrete ACO algorithm over the variable selection. According to information positive feedback and indirect communication mechanism of ACO, a modified ACO for variable selection is proposed.

For Variable selection problem expressed in binary notation, an ant moves in a binary notation, an ant moves in a $\mathrm{N}$ dimensional search space of $\mathrm{N}$ variables, its motion is restricted to either 0 or 1 on each dimension. Every ant selects the variables depending upon the moving probability of 0 or 1 . If the variable is selected then it can be shown by 1 else 0 .

In the Variable selection problems the concept of pheromone trail intensity is different from ordering problems; here the pheromone levels on each dimension are divided into two kinds, $\tau_{i 1}^{k}$ and $\tau_{i 0}^{k}$ which represent the pheromone of dimension i taking the value 1 and 0 , respectively. The pheromone levels are updated according to the updating rule (Shen et al, 2005).

$$
\begin{aligned}
& \tau_{i 0}(\text { new })=\rho \tau_{i 0}(\text { old })+\Delta \tau_{i 0} \\
& \Delta \tau_{i 0}=\sum_{k=1}^{m} \Delta \tau_{i 0}^{k} \\
& \tau_{i 1}(\text { new })=\rho \tau_{i 1}(\text { old })+\Delta \tau_{i 1} \\
& \Delta \tau_{i 1}=\sum_{k=1}^{m} \Delta \tau_{i 1}^{k}
\end{aligned}
$$

For each dimension, the intensity of the pheromone at time 0 is set to 0 .

$\Delta \tau_{i 1}=\mathrm{F}+\mathrm{F}_{\mathrm{H}}$ if $\mathrm{k}^{\text {th }}$ ant selected variable $\mathrm{i}$ both in the current iteration and in its global best solution

$\Delta \tau_{i 1}=\mathrm{F} \quad$ if $\mathrm{k}^{\text {th }}$ ant selected variable $\mathrm{i}$ only in the current iteration

$\Delta \tau_{\mathrm{i} 1}=\mathrm{F}_{\mathrm{H}} \quad$ if $\mathrm{k}^{\text {th }}$ ant selected variable $\mathrm{i}$ only in its historical global best solution.

$\Delta \tau_{i 0}=F+F_{H}$ if variable $i$ was not selected by ant $\mathrm{k}$ in the current iteration either in its historical global best solution

$\Delta \tau_{i 0}=\mathrm{F} \quad$ if variable $\mathrm{i}$ was not selected by ant $\mathrm{k}$ in current iteration

$\Delta \tau_{\mathrm{i} 0}=\mathrm{F}_{\mathrm{H}} \quad$ if variable $\mathrm{i}$ was not selected by ant $\mathrm{k}$ in its historical global best solution

Where $\mathrm{F}$ and $\mathrm{F}_{\mathrm{H}}$ are defined by fitness function. For improving the convergence velocity, the information $\mathrm{F}_{\mathrm{H}}$ which corresponds to the historical global best result of the $\mathrm{i}^{\text {th }}$ ant was introduced to the increment of pheromone. An ant $\mathrm{K}$ makes a decision concerning the variable selection according to the pheromone amount. The moving probability is given by equation 10 :

$$
P_{i}^{k}=\frac{\tau_{i 1}^{k}}{\tau_{i 1}^{k}+\tau_{i 0}^{k}}
$$




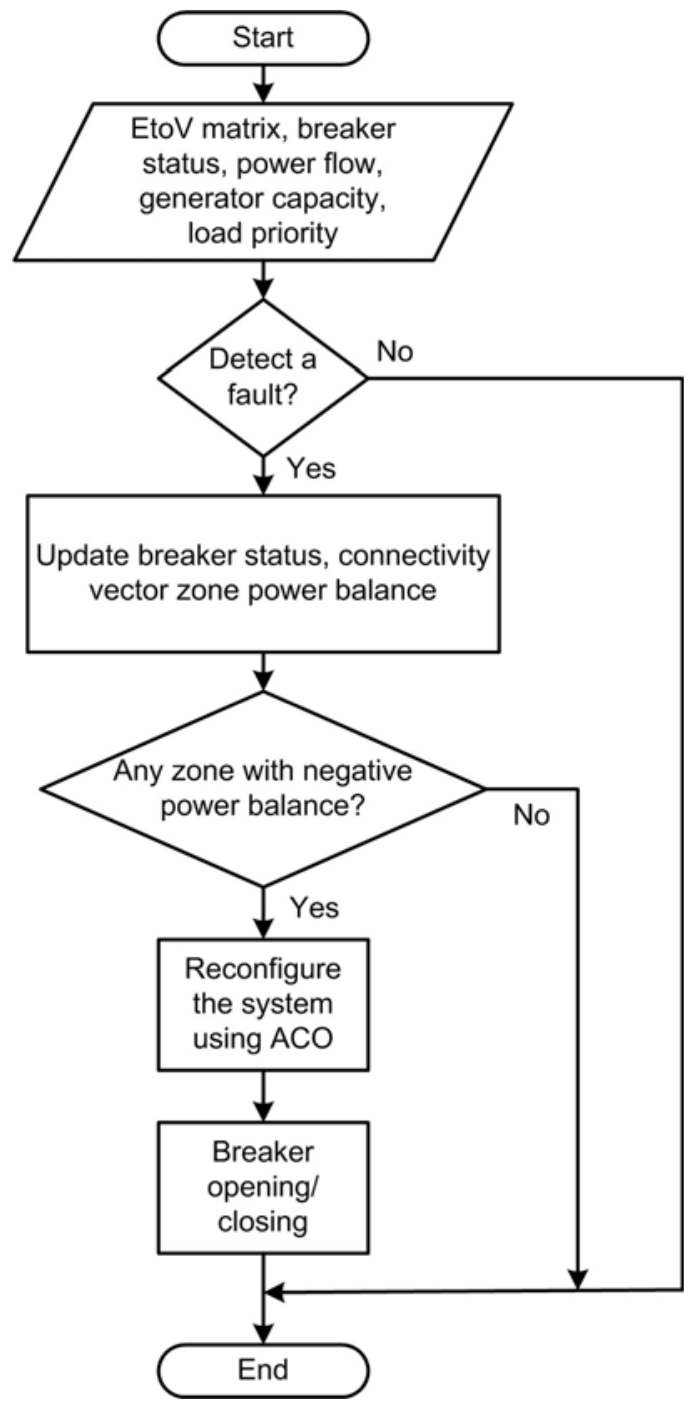

Figure 3. Flow chart of reconfiguration procedure using ACO

In the modified ACO, $\mathrm{m}$ ants select variables from all $\mathrm{N}$ variables, according to the probability. After selection, the amount of pheromone is updated. This process is iterated until the minimum error criterion is attained or the number of iteration reaches a user defined limit.

To apply developed ant colony technique for reconfiguration, power system need to be simplified using graph theory. After simplifying a power system topology into a graph, the corresponding matrices can represent the graph mathematically for computer implementation. These matrices include breaker-to-zone matrix, breaker status matrix, generator capacity matrix, load priority matrix and power flow matrix. When the power system experiences fault(s), the fault detection functions will quickly locate the fault and issue a trip signal to the breakers surrounding the faulted zone to isolate the fault. Then the breaker-to-zone matrix will be updated by removing the isolated zones and tripped breakers. The zone balance matrix will be calculated to find out any negative zones. The path searching function is then activated to find out possible power supply paths for these negative zones. All the loads and generators are extracted along the path and then ACO is used for restoration and load shedding if necessary. The flow chart of the reconfiguration process is shown in figure 3.

\section{Results}

The reconfiguration process using ACO has been developed and implemented in MATLAB. The algorithms have been tested on an 8-bus power system model and on 13-bus power system model with distributed generators. Loads are served on the basis of load magnitude only, load priority only, as well as both load magnitude and load priority. For 8 bus power system shown in figure 1, loads 2, 3, and 6 have higher priority than loads 1, 4 and 5. Several test case scenarios have been created by simulating fault at different buses or combinations of buses to make it total of 8 test case scenarios. 
Table 3. Based on Load Magnitude for 8-bus SPS

\begin{tabular}{|c|c|c|c|c|c|c|}
\hline $\begin{array}{l}\text { Test } \\
\text { case }\end{array}$ & $\begin{array}{l}\text { Faulted } \\
\text { Bus } \\
\text { Number }\end{array}$ & $\begin{array}{l}\text { Negative } \\
\text { power bus }\end{array}$ & Possible power supply path & $\begin{array}{c}\text { Load } \\
\text { Shedding }\end{array}$ & $\begin{array}{l}\text { Breaker } \\
\text { reconfiguration }\end{array}$ & $\begin{array}{l}\text { MW } \\
\text { Served }\end{array}$ \\
\hline Case1 & B1 & B2 & B2-B3-B4-B5-B6-B7-B8 & L4 & $\begin{array}{l}\text { BK 11, 1, 2, 3, } 18(\mathrm{O}) \\
\text { BK 5, 8, 9, } 14(\mathrm{C})\end{array}$ & 44 \\
\hline Case2 & B3 & No & No & No & BK $6,7(\mathrm{O})$ & 47 \\
\hline Case3 & B5 & B6 & B6-B7-B8-B1-B2-B3-B4 & L1 & $\begin{array}{c}\text { BK 2, 10, 11, } 12(\mathrm{O}) \\
\text { BK } 14,5,8(\mathrm{C})\end{array}$ & 44 \\
\hline Case4 & B7 & No & No & No & BK 15, 16, $17(\mathrm{O})$ & 47 \\
\hline Case5 & $\mathrm{B} 1, \mathrm{~B} 3$ & $\mathrm{~B} 2$ & No possible generation & L2 & (BK 4, 1, 2, 3, 18, 6, 7(O) & 24 \\
\hline Case6 & B1, B5 & $\begin{array}{l}\mathrm{B} 6 \\
\mathrm{~B} 2\end{array}$ & $\begin{array}{l}\text { B6-B7-B8 } \\
\text { B2-B3-B4 }\end{array}$ & $\begin{array}{l}\text { L2 } \\
\text { L5 }\end{array}$ & $\begin{array}{c}\text { BK 4, 13, 1, } 2,3,18,10,11,12(\mathrm{O}) \\
\text { BK 5, 8, } 14(\mathrm{C})\end{array}$ & $\begin{array}{l}2 \\
2 \\
\end{array}$ \\
\hline Case7 & B3, B7 & No & No & No & BK $6,7,15,16,17(\mathrm{O})$ & 44 \\
\hline Case8 & B5, B7 & B6 & No possible generation & L5 & $\mathrm{BK} 13,10,11,12,15,16,17(\mathrm{O})$ & 24 \\
\hline
\end{tabular}

In the table 3, for a particular fault bus, the negative bus formed is shown with the possible power paths and corresponding load shedding. Amount of load served in MW and the breaker reconfiguration showing open and close status are also shown.

Table 4 shows the test results for eight bus power system with consideration of load priority. In case 1, when the fault happened on bus 1 and protection system isolate bus 1 from rest of the system, bus 2 had negative power balance of -20MW, which means that bus 2 imported 20MW power from faulted bus 1 before fault occurred. Then, the reconfiguration algorithm started to search possible paths with non-negative power balance for the negative power bus 2. The only possible path found was B2-B3-B4-B5B6-B7-B8 using graph theory. All the loads and generators are extracted along this path using the ant colony algorithm to restore the loads based on the priority and the available generation. In this case the generation was found to be $44 \mathrm{MW}$ and the total load was $46 \mathrm{MW}$. So load 4 (L4) was shed because it has lowest priority compared to other loads and the remaining loads are restored along the path. In case 6, two faults happened on bus 1 and bus 5 . After fault isolation, bus 2 and bus 6 both have a power deficit. In this case two islands were formed corresponding to two negative buses. Possible power supply paths are B2-B3-B4 and B6-B7B8. Ant Colony algorithm was applied separately for each island and loads L2 and L5 were shed even though they have the highest priority because there was not enough power generation. It can be seen from table 3 and 4, that there are not much differences in results obtained for load magnitude and load priority. The reason for similarity between these results are less available options for optimization given small test system with only two generators and two distributed generations.

Table 4. Based on Load Priority for 8-bus SPS

\begin{tabular}{|c|c|c|c|c|c|c|}
\hline $\begin{array}{l}\text { Test } \\
\text { Case }\end{array}$ & $\begin{array}{c}\text { Faulted } \\
\text { Bus } \\
\text { Number }\end{array}$ & $\begin{array}{l}\text { Negative } \\
\text { power bus }\end{array}$ & $\begin{array}{l}\text { Possible } \\
\text { power } \\
\text { supply path }\end{array}$ & $\begin{array}{c}\text { Load } \\
\text { Shedding }\end{array}$ & $\begin{array}{c}\text { Breaker } \\
\text { Reconfiguration }\end{array}$ & $\begin{array}{l}\text { MW } \\
\text { Served }\end{array}$ \\
\hline Case 1 & B1 & B2 & B2-B3-B4-B5-B6-B7-B8 & L4 & $\begin{array}{l}\text { BK 11, 1, 2, 3, } 18(\mathrm{O}) \\
\text { BK 5, 8, 9, } 14(\mathrm{C})\end{array}$ & 44 \\
\hline Case2 & B3 & No & No & No & "BK 6,7 (O) & 46 \\
\hline Case 3 & B5 & B6 & B6-B7-B8-B1-B2-B3-B4 & L1 & $\begin{array}{c}\text { BK } 2,10,11,12(\mathrm{O}) \\
\text { BK } 14,5,8(\mathrm{C})\end{array}$ & 44 \\
\hline Case4 & B7 & No & No & No & BK $15,16,17(\mathrm{O})$ & 46 \\
\hline Case 5 & $\mathrm{~B} 1, \mathrm{~B} 3$ & B2 & $\begin{array}{l}\text { No possible } \\
\text { generation }\end{array}$ & $\mathrm{L} 2$ & $\mathrm{BK} 4,1,2,3,18,6,7(\mathrm{O})$ & 24 \\
\hline Case6 & $\mathrm{B} 1, \mathrm{~B} 5$ & $\begin{array}{l}\mathrm{B} 6 \\
\mathrm{~B} 2\end{array}$ & $\begin{array}{l}\mathrm{B} 6-\mathrm{B} 7-\mathrm{B} 8 \\
\mathrm{~B} 2-\mathrm{B} 3-\mathrm{B} 4\end{array}$ & $\begin{array}{l}\mathrm{L} 2 \\
\mathrm{~L} 5\end{array}$ & $\begin{array}{c}\text { BK } 4,13,1,2,3,18,10,11,12(\mathrm{O}) \\
\text { BK } 5,8,14(\mathrm{C})\end{array}$ & $\begin{array}{l}1 \\
1\end{array}$ \\
\hline Case7 & B3, B7 & No & No & No & BK $6,715,16,17(\mathrm{O})$ & 44 \\
\hline Case8 & B5, B7 & B6 & $\begin{array}{l}\text { No possible } \\
\text { generation }\end{array}$ & L5 & $\mathrm{BK} 13,10,11,12,15,16,17$ (O) & 24 \\
\hline
\end{tabular}


Table 5. Based on Load Magnitude and Priority for 8-bus SPS

\begin{tabular}{|c|c|c|c|c|c|c|}
\hline $\begin{array}{l}\text { Test } \\
\text { Case }\end{array}$ & \begin{tabular}{|c|} 
Faulted \\
Bus \\
Number
\end{tabular} & $\begin{array}{c}\text { Negative } \\
\text { power } \\
\text { bus }\end{array}$ & $\begin{array}{l}\text { Possible power } \\
\text { supply path }\end{array}$ & $\begin{array}{c}\text { Load } \\
\text { Shedding }\end{array}$ & $\begin{array}{l}\text { Breaker } \\
\text { reconfiguration }\end{array}$ & $\begin{array}{l}\text { MW } \\
\text { Served }\end{array}$ \\
\hline Case1 & B1 & B2 & B2-B3-B4-B5-B6-B7-B8 & L6 & $\begin{array}{c}\text { BK } 15,1,2,3,18(\mathrm{O}) \\
\text { BK } 5,8,9,14(\mathrm{C})\end{array}$ & 44 \\
\hline Case2 & B3 & No & No & No & BK $6,7(\mathrm{O})$ & 46 \\
\hline Case 3 & B5 & B6 & B6-B7-B8-B1-B2-B3-B4 & L6 & $\begin{array}{c}\text { BK 15, 10,11, } 12(\mathrm{O}) \\
\text { BK } 14,5,8(\mathrm{C})\end{array}$ & 44 \\
\hline Case4 & B7 & No & No & No & BK $15,16,17(\mathrm{O})$ & 46 \\
\hline Case 5 & $\mathrm{~B} 1, \mathrm{~B} 3$ & B2 & $\begin{array}{c}\text { No possible } \\
\text { generation }\end{array}$ & $\mathrm{L} 2$ & $\mathrm{BK} 4,1,2,3,18,6,7(\mathrm{O})$ & 24 \\
\hline Case6 & $\mathrm{B} 1, \mathrm{~B} 5$ & $\begin{array}{l}\text { B6 } \\
\text { B2 }\end{array}$ & $\begin{array}{l}\text { B6-B7-B8 } \\
\text { B2-B3-B4 }\end{array}$ & $\begin{array}{l}\text { L2 } \\
\text { L5 }\end{array}$ & $\begin{array}{c}\text { BK 4, } 13,1,2,3,18,10,11,12(\mathrm{O}) \\
\text { BK } 5,8,14(\mathrm{C})\end{array}$ & $\begin{array}{l}1 \\
1\end{array}$ \\
\hline Case 7 & B3, B7 & $\overline{\text { No }}$ & $\overline{\mathrm{No}}$ & $\overline{\text { No }}$ & BK $6,715,16,17(\mathrm{O})$ & $\overline{44}$ \\
\hline Case8 & B5, B7 & B6 & $\begin{array}{l}\text { No possible } \\
\text { generation }\end{array}$ & L5 & BK 13, 10, 11, 12, 15, 16, $17(\mathrm{O})$ & 24 \\
\hline
\end{tabular}

Test results for simulations objective of maximizing the load magnitude and priority for eight bus SPS. As shown in table 3,4 and 5, those results for this particular scenario is similar to reconfiguration with load priority.

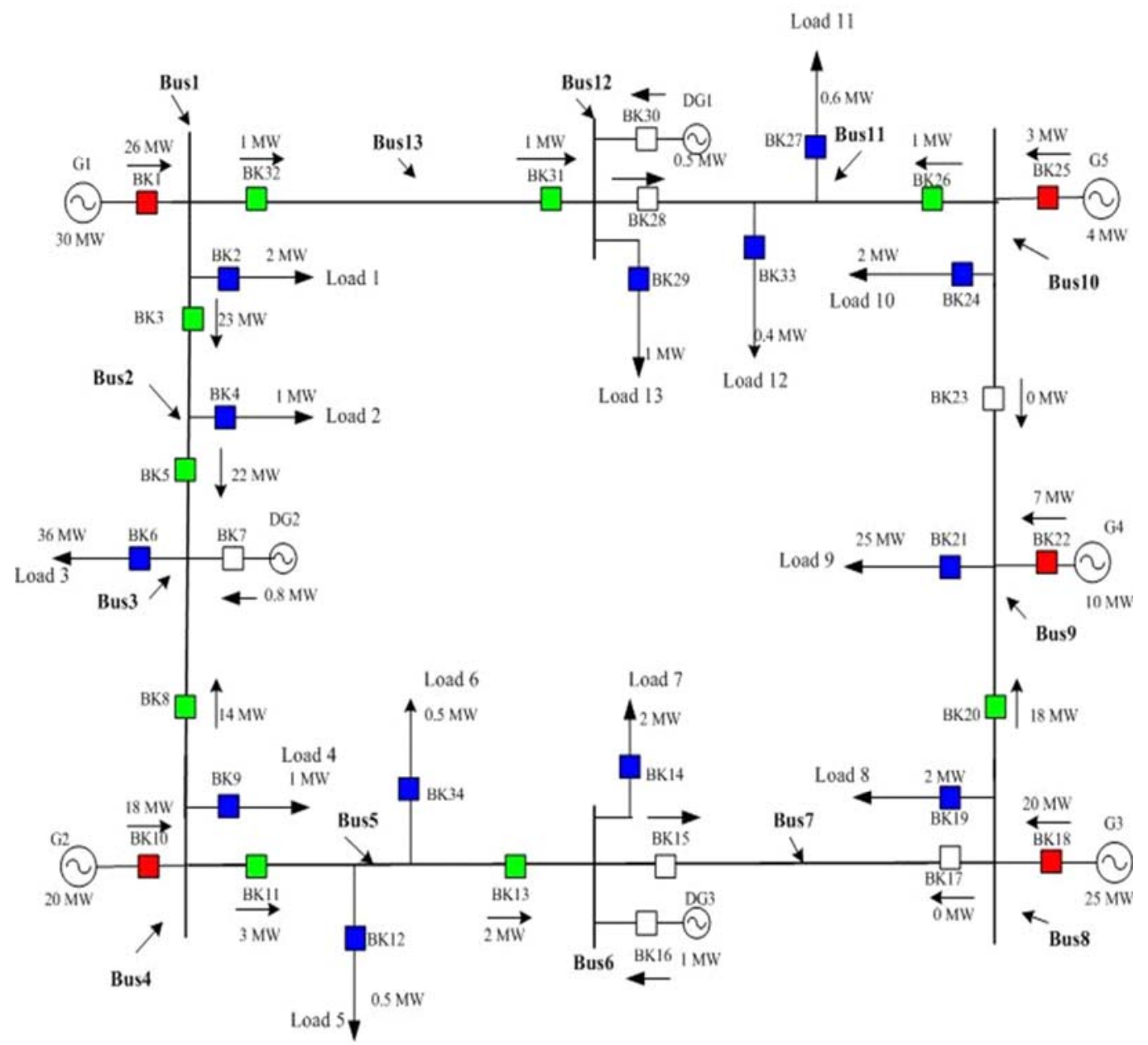

Figure 4. 13-bus Shipboard Power System with Distributed Generators 
Developed reconfiguration algorithm was also tested on bigger shipboard power system with thirteen buses. This system has 5 generators and 3 distributed generators as shown in figure 4. There are 13 loads with different MW value in the system. There are more number of possible options to reconfigure the network in this system compared to eight bus power system shown in figure 1 . Table 6 shows the priority preferences for all the loads for thirteen bus SPS.

Table 6. Load Priority for 13-bus SPS

\begin{tabular}{|l|l|}
\hline Load & Priority \\
\hline Load 1 & Semi-vital \\
\hline Load 2 & Non-vital \\
\hline Load 3 & Semi-vital \\
\hline \hline Load 4 & Non-vital \\
\hline Load 5 & Semi-vital \\
\hline Load 6 & Non-vital \\
\hline Load 7 & Vital \\
\hline Load 8 & Non-vital \\
\hline Load 9 & Vital \\
\hline \hline Load 10 & Semi-vital \\
\hline Load 11 & Non-vital \\
\hline Load 12 & Semi-vital \\
\hline Load 13 & Non-vital \\
\hline
\end{tabular}

Test case 2, 13 bus SPS was represented by graph theory in matrices form similar to eight bus power system to apply ACO reconfiguration algorithm. Table 7, 8 and 9 shows the simulation results for optimization based on load priority, load magnitude and simultaneous optimization of load magnitude and load priority.

Table 7. Based on Load Priority for 13-bus SPS

\begin{tabular}{|c|c|c|c|c|c|c|}
\hline $\begin{array}{l}\text { Test } \\
\text { case }\end{array}$ & \begin{tabular}{|l|} 
Faulted \\
Bus \\
Number \\
\end{tabular} & \begin{tabular}{|c|}
$\begin{array}{c}\text { Negative } \\
\text { power } \\
\text { bus }\end{array}$ \\
\end{tabular} & $\begin{array}{l}\text { Possible power } \\
\text { supply path }\end{array}$ & $\begin{array}{l}\text { Load } \\
\text { Shedding }\end{array}$ & $\begin{array}{c}\text { Breaker } \\
\text { Reconfiguration }\end{array}$ & $\begin{array}{l}\text { MW } \\
\text { Served }\end{array}$ \\
\hline Case 1 & B1 & $\mathrm{B} 2, \mathrm{~B} 13$ & \begin{tabular}{|} 
B2-B3-B4-B5-B6-B7-B8- \\
B9-B10-B11-B12-B13
\end{tabular} & L3 & $\begin{array}{c}\text { BK 1,2,3,6, 32(O) } \\
\text { BK } 15,17,23,28,7,16,30(\mathrm{C})\end{array}$ & 36 \\
\hline Case 2 & B4 & $\mathrm{B} 3, \mathrm{~B} 5$ & \begin{tabular}{|c|} 
B3-B2-B1-B13-B12-B11- \\
B10-B9-B8-B7-B6-B5 \\
\end{tabular} & L2, L13 & $\begin{array}{r}\text { BK } 4,8,9,10,11,29(\mathrm{O}) \\
\text { BK } 28,33,17,15,7,16,30(\mathrm{C}) \\
\end{array}$ & 71 \\
\hline Case 3 & B8 & B9 & $\begin{array}{l}\text { B9-B10-B11-B12-B13- } \\
\text { B1-B2-B3-B4-B5-B6-B7 }\end{array}$ & $\begin{array}{l}\text { L2, L4, L6, L10, } \\
\text { L11,L13 }\end{array}$ & $\begin{array}{c}\text { BK 4, 9, 34, } 24 \text { 27, 29, 18, 19, } 20 \\
\text { (O) } \\
\text { BK 23, 28, 15, 7, 16, } 30 \text { (C) }\end{array}$ & 65.9 \\
\hline Case 4 & B9 & No & No & No & BK 20, 21, $22(\mathrm{O})$ & 49 \\
\hline Case 5 & $\mathrm{~B} 10$ & B11 & B11-B12-B13-B1 & No & BK 24, 25, $26(\mathrm{O})$ & 72 \\
\hline Case 6 & B1, B4 & $\begin{array}{c}\text { B2 } \\
\text { B3 } \\
\text { B5 } \\
\text { B13 } \\
\end{array}$ & $\begin{array}{c}\mathrm{B} 2-\mathrm{B} 3 \\
\mathrm{~B} 5-\mathrm{B} 6-\mathrm{B} 7-\mathrm{B} 8-\mathrm{B} 9 \\
\mathrm{~B} 13-\mathrm{B} 12-\mathrm{B} 11-\mathrm{B} 10\end{array}$ & \begin{tabular}{|}
$\mathrm{L} 2, \mathrm{~L} 3, \mathrm{~L} 6, \mathrm{~L} 7, \mathrm{~L} 8, \mathrm{~L} 9, \mathrm{~L} 10$ \\
$\mathrm{~L} 11, \mathrm{~L} 12, \mathrm{~L} 13$
\end{tabular} & $\begin{array}{c}\text { BK 4, } 6,1,2,3,32,8,9,10, \\
11,34,14,19,25,24,27,33,29(\mathrm{O})\end{array}$ & 0.5 \\
\hline Case 7 & B1, B8 & $\begin{array}{l}\text { B2 } \\
\text { B9 } \\
\text { B13 }\end{array}$ & $\begin{array}{l}\text { B2-B3-B4-B5-B6-B7 } \\
\text { B9-B10-B11-B12-B13 }\end{array}$ & $\begin{array}{l}\text { L3 } \\
\text { L9 }\end{array}$ & $\begin{array}{l}\text { BK } 6,21,1,2,3,32,18,19,20(\mathrm{O}) \\
\quad \text { BK } 7,15,16,23,28,30(\mathrm{C})\end{array}$ & 9 \\
\hline Case 8 & $\mathrm{~B} 4, \mathrm{~B} 10$ & $\begin{array}{l}\text { B3 } \\
\text { B5 } \\
\text { B11 }\end{array}$ & $\begin{array}{c}\text { B3-B2-B1-B13-B12-B11 } \\
\text { B5-B6-B7-B8-B9 }\end{array}$ & L3,L8,L13 & $\begin{array}{c}\text { BK } 6,8,9,10,11,24,25,26,19,29 \\
(\mathrm{O}) \\
\text { BK } 7,15,16,28,30(\mathrm{C})\end{array}$ & 32 \\
\hline
\end{tabular}


Table 8. Based on Load Magnitude for 13-bus SPS

\begin{tabular}{|c|c|c|c|c|c|c|}
\hline $\begin{array}{l}\text { Test } \\
\text { case }\end{array}$ & $\begin{array}{l}\text { Faulted } \\
\text { Bus } \\
\text { Number }\end{array}$ & $\begin{array}{c}\text { Negative } \\
\text { power } \\
\text { bus }\end{array}$ & $\begin{array}{l}\text { Possible power } \\
\text { supply path }\end{array}$ & $\begin{array}{c}\text { Load } \\
\text { Shedding }\end{array}$ & $\begin{array}{l}\text { Breaker } \\
\text { reconfiguration }\end{array}$ & $\begin{array}{l}\text { MW } \\
\text { Served }\end{array}$ \\
\hline Case1 & B1 & $\mathrm{B} 2, \mathrm{~B} 13$ & $\begin{array}{l}\text { B2-B3-B4-B5-B6-B7-B8- } \\
\text { B9-B10-B11-B12-B13 }\end{array}$ & $\begin{array}{l}\mathrm{L} 2, \mathrm{~L} 4, \mathrm{~L} 5, \mathrm{~L} 6, \mathrm{~L} 7, \mathrm{~L} 8, \mathrm{~L} 10 \\
\mathrm{~L} 11, \mathrm{~L} 12, \mathrm{~L} 13\end{array}$ & $\begin{array}{c}\text { BK 1, 2, 3, } \\
32,4,9,12,34,14,19,24,27,33(\mathrm{O}) \\
\text { BK } 15,17,23,28,7,16,30(\mathrm{C}) \\
\end{array}$ & 62 \\
\hline Case2 & B4 & $\mathrm{B} 3, \mathrm{~B} 5$ & $\begin{array}{l}\text { B3-B2-B1-B13-B12-B11- } \\
\text { B10-B9-B8-B7-B6-B5 }\end{array}$ & L12, L6, L13 & $\begin{array}{c}\text { BK } 33,34,29,910,11(\mathrm{O}) \\
\text { BK } 28,23,17,15,7,16,30(\mathrm{C})\end{array}$ & 71.1 \\
\hline Case3 & B8 & B9 & \begin{tabular}{|c|} 
B9-B10-B11-B12-B13-B1- \\
B2-B3-B4-B5-B6-B7
\end{tabular} & L1, L5, L7, L12, L13 & $\begin{array}{c}\text { BK 2,14,33,17, 29, 18, 19, } 20(\mathrm{O}) \\
\text { BK } 23,28,15,7,16,30(\mathrm{C})\end{array}$ & 66.1 \\
\hline Case4 & B9 & No & No & No & BK $20,21,22(\mathrm{O})$ & 49 \\
\hline Case5 & $\mathrm{B} 10$ & B11 & B11-B12-B13-B1 & No & BK 24, 25, $26(\mathrm{O})$ & 72 \\
\hline Case6 & B1, B4 & $\begin{array}{c}\text { B2 } \\
\text { B3 } \\
\text { B5 } \\
\text { B13 } \\
\end{array}$ & $\begin{array}{c}\text { B2-B3 } \\
\text { B5-B6-B7-B8-B9 } \\
\text { B13-B12-B11-B10 }\end{array}$ & $\begin{array}{c}\mathrm{L} 2, \mathrm{~L} 3, \mathrm{~L} 5, \mathrm{~L} 7, \mathrm{~L} 8, \mathrm{~L} 9, \mathrm{~L} 10 \\
\mathrm{~L} 11, \mathrm{~L} 12, \mathrm{~L} 13\end{array}$ & $\begin{array}{c}\text { BK } 4,6,1,2,3,32,8,9,10, \\
11,12,14,19,25,24,27,33,29(\mathrm{O})\end{array}$ & 0.5 \\
\hline Case 7 & $\mathrm{~B} 1, \mathrm{~B} 8$ & $\begin{array}{c}\text { B2 } \\
\text { B9 } \\
\text { B13 } \\
\end{array}$ & $\begin{array}{l}\text { B2-B3-B4-B5-B6-B7 } \\
\text { B9-B10-B11-B12-B13 }\end{array}$ & $\begin{array}{l}\text { L3 } \\
\text { L9 }\end{array}$ & $\begin{array}{c}\text { BK } 6,21,1,2,3,32,18,19,20 \\
\text { BK } 7,15,23,28,30(\mathrm{C})\end{array}$ & $\begin{array}{l}5 \\
4\end{array}$ \\
\hline Case8 & $\mathrm{B} 4, \mathrm{~B} 10$ & $\begin{array}{l}\text { B3 } \\
\text { B5 } \\
\text { B11 } \\
\end{array}$ & $\begin{array}{c}\text { B3-B2-B1-B13-B12-B11 } \\
\text { B5-B6-B7-B8-B9 }\end{array}$ & L1,L2,L3,L6,L12 & $\begin{array}{c}\text { BK } 6,8,9,10,11,24,25, \\
26,2,4,34,33(\mathrm{O}) \\
\text { BK } 7,15,16,28,30(\mathrm{C}) \\
\end{array}$ & 31.1 \\
\hline
\end{tabular}

As shown in the table, optimization with load magnitude has more MW served compared to MW served with load priority. It is also evident from these results that high priority loads do not get shed in reconfiguration algorithm as shown in table 7. Similar to eight bus test cases, several test case scenarios have been created by simulating fault at different buses or combinations of buses to make it total of 8 test case scenarios for 13-bus test case. Numbers of negative power buses are generally more for multiple bus faults, as expected.

Table 9. Based on Load Magnitude and priority for 13-bus SPS

\begin{tabular}{|c|c|c|c|c|c|c|}
\hline $\begin{array}{l}\text { Test } \\
\text { case }\end{array}$ & $\begin{array}{c}\text { Faulted } \\
\text { Bus } \\
\text { Number } \\
\end{array}$ & \begin{tabular}{|c|}
$\begin{array}{c}\text { Negative } \\
\text { power } \\
\text { bus }\end{array}$ \\
\end{tabular} & $\begin{array}{l}\text { Possible power } \\
\text { supply path }\end{array}$ & $\begin{array}{c}\text { Load } \\
\text { Shedding }\end{array}$ & $\begin{array}{l}\text { Breaker } \\
\text { reconfiguration }\end{array}$ & $\begin{array}{l}\text { MW } \\
\text { Served }\end{array}$ \\
\hline Case1 & B1 & $\mathrm{B} 2, \mathrm{~B} 13$ & $\begin{array}{c}\text { B2-B3-B4-B5-B6-B7-B8-B9- } \\
\text { B10-B11-B12-B13 }\end{array}$ & L3 & $\begin{array}{c}\text { BK } 6,1,2,3,32(\mathrm{O}) \\
\text { BK } 15,17,23,28,7,16,30(\mathrm{C})\end{array}$ & 36 \\
\hline Case2 & B4 & B3, B5 & $\begin{array}{l}\text { B3-B2-B1-B13-B12-B11- } \\
\text { B10-B9-B8-B7-B6-B5 }\end{array}$ & L2,L13 & $\begin{array}{c}\text { BK } 4,29,8,9,10,11(\mathrm{O}) \\
\text { BK } 28,33,17,15,7,16,30(\mathrm{C})\end{array}$ & 71 \\
\hline Case3 & B8 & B9 & $\begin{array}{l}\text { B9-B10-B11-B12-B13-B1- } \\
\text { B2-B3-B4-B5-B6-B7 }\end{array}$ & $\begin{array}{l}\text { L2, L4, L6,L10, } \\
\text { L11,L13 } \\
\end{array}$ & $\begin{array}{c}\text { BK } 4,9,34,24,27,29,18,19,20(\mathrm{O}) \\
\text { BK } 23,28,15,7,16,30(\mathrm{C}) \\
\end{array}$ & 65.9 \\
\hline Case4 & B9 & No & No & No & BK $20,21,22(\mathrm{O})$ & 49 \\
\hline Case5 & B10 & B11 & B11-B12-B13-B1 & No & BK 24, 25, $26(\mathrm{O})$ & 72 \\
\hline Case6 & B1, B4 & $\begin{array}{c}\text { B2 } \\
\text { B3 } \\
\text { B5 } \\
\text { B13 } \\
\end{array}$ & $\begin{array}{c}\mathrm{B} 2-\mathrm{B} 3 \\
\mathrm{~B} 5-\mathrm{B} 6-\mathrm{B} 7-\mathrm{B} 8-\mathrm{B} 9 \\
\mathrm{~B} 13-\mathrm{B} 12-\mathrm{B} 11-\mathrm{B} 10\end{array}$ & $\begin{array}{l}\text { L2,L3,L6,L7,L8,L9, } \\
\text { L10,L11,L12,L13 }\end{array}$ & $\begin{array}{c}\text { BK 4, } 6,1,2,3,32,8,9,10, \\
11,34,14,19,25,24,27,33,29(\mathrm{O})\end{array}$ & 0.5 \\
\hline Case7 & B1, B8 & $\begin{array}{c}\mathrm{B} 2 \\
\mathrm{~B} 9 \\
\mathrm{~B} 13\end{array}$ & $\begin{array}{l}\text { B2-B3-B4-B5-B6-B7 } \\
\text { B9-B10-B11-B12-B13 }\end{array}$ & $\begin{array}{l}\text { L3 } \\
\text { L9 }\end{array}$ & $\begin{array}{c}\text { BK } 6,21,1,2,3,32,18,19,20(\mathrm{O}) \\
\text { BK } 7,15,23,28(\mathrm{C})\end{array}$ & 9 \\
\hline Case8 & $\mathrm{B} 4, \mathrm{~B} 10$ & $\begin{array}{c}\text { B3 } \\
\text { B5 } \\
\text { B11 }\end{array}$ & $\begin{array}{l}\text { B3-B2-B1-B13-B12-B11 } \\
\text { B5-B6-B7-B8-B9 }\end{array}$ & L3,L2,L8,L13 & $\begin{array}{c}\text { BK } 6,8,9,10,11,24,25,26,4,19,29 \\
(\mathrm{O}) \\
\text { BK } 7,15,16,28,30(\mathrm{C})\end{array}$ & 31 \\
\hline
\end{tabular}


130 Vuppalapati and Srivastava / International Journal of Engineering, Science and Technology, Vol. 2, No. 3, 2010, pp. 119-131

Similar to eight bus test cases, test results for simulations objective of maximizing the load magnitude and priority is similar to reconfiguration with load priority. There are several other test cases scenarios for different fault scenarios are also simulated and satisfactorily results were obtained. Those results are not presented here and only 8 test scenarios have been shown in these tables.

\section{Conclusions}

The reconfiguration problem for shipboard power system was investigated using novel application of ant colony and graph theory. Graph theory is used to represent the shipboard power system and ant colony was used to maximize the load magnitude or load priority. The mathematical problems were formulated to maximize the objective function considering (i) load magnitude only (ii) load priority only (iii) both load magnitude and load priority. Developed ant colony optimization technique has been tested for two test cases under several fault scenarios. Simulation results obtained are satisfactory and proposed method can be easily extended for application to bigger distributed power system.

\section{Acknowledgement}

Authors would like to thank financial support provided by the Office of Naval Research (ONR) under Grant N00014-02-1-0623.

\section{References}

Ahuja, A. Das, S., and Pahwa A. 2007. An AIS-ACO hybrid approach for multi-objective distribution system reconfiguration. IEEE Transactions on Power Systems. Vol. 22, No. 3, pp. 1101-1111.

Bulter K. L., Sarma N. D. R. 2000. General reconfiguration methodology for AC radial shipboard power systems. IEEE 2000 Power Engineering Society Winter Meeting. pp. 1226-1230.

Bulter K. L., Sarma N. D. R. and Prasad V. R. 1999. A new method of network reconfiguration for service restoration in shipboard power systems. Proc. of IEEE Power Engineering Society Transmission and Distribution Conf, pp. 658-662.

Bulter K. L., Sarma N. D. R., and Prasad V. R. 2001. Network reconfiguration for service restoration in shipboard power distribution system. IEEE Transactions on Power System. Vol. 16, No. 4, pp. 653-661.

Daniel C. L., Khan, H. I., and Ravichandran S. 2005. Distribution network reconfiguration for loss reduction using ant colony algorithm. Annual IEEE India Conference (Indicon), pp. 619-622.

Davey K. R., and Hebner, R. E. 2005. Reconfiguration: A tool for designing new ships. IEEE Electric Ship Technologies Symposium (ESTS). Philadelphia, Pennsylvania, U.S.A.

Dorigo M. and Stutzle, T. 2004. Ant Colony Optimization. A Bradford book. MIT press, Cambridge, MA, USA.

Dorigo, M., and Gambardella, L. M. 1997. Ant colony system: a cooperative learning approach to the traveling salesman problem. IEEE transcations on Evolutionary Computation. Vol. 1, No. 1, pp. 53- 66.

Hamdaoui H., Hadjeri, S. and Zeblah, A. 2008. A new constructive method for electrical power system using ant colony. Leonardo Electronic Journal of practices and Technologies. Vol. 7, No. 12, pp. 49-60.

Haung Y. 2006. Fast Reconfiguration Algorithm Development for Shipboard Power Systems. M.S. thesis, Dept. of Electrical Eng. Mississippi State University, MS, USA.

Huang K, Srivastava S.K., Cartes D.A., and Sun L.-H. 2009. Market-based multiagent system for reconfiguration of shipboard power systems. Electric Power Systems Research, Vol. 79, No. 4, pp. 550-556.

Jayabalan, R., and Fahimi, B. 2005. Naval shipboard power system. IEEE Vehicle Power and Propulsion Conference. Chicago, IL.

Kleppinger D., Broadwater R., and Scirbona C. 2010. Generic reconfiguration for restoration. Electric Power Systems Research. Vol. 80, issue 3, pp. 287-295.

Kumar N., Srivastava, A. K., and Schulz, N. N. 2007. Shipboard power system restoration using binary particle swarm optimization. $39^{\text {th }}$ North American Power Symposium, (NAPS). pp. 164-169.

Leiguizamon G. and Michalewicz Z. 1999. A new Version of ant system for subset problems. Proceedings of the congress on Evolutionary Computation. Vol. 2.

Luan W. P., Irving, M. R., and Daniel, J. S. 2002. Genetic algorithm for supply restoration and optimal load shedding in power system distribution networks. IEE Proceedings of Generation, Transmission and Distribution. Vol. 149, No.2, pp. 145-151.

Meek, C. D. 2004. Investigation of optimization methods used for reconfiguration of the naval electric ship power system. M. S. thesis, University of Texas, Austin.

Padamati, K. R., Schulz N. N., and Srivastava A. K. 2007. Application of genetic algorithm for reconfiguration of shipboard power system. $39^{\text {th }}$ North American Power Symposium, (NAPS). pp. 159-163.

Pendurthi, V.K., Schulz, N.N., Doane, S., and Srivastava, A.K. 2009. Cognitive engineering studies of DSS and dealing with uncertainty in load for real-time adaptive power system reconfiguration. IEEE Electric Ship Technologies Symposium. pp. 79 85. 
Shen Q., Jiang, J. H., Tao, J. C., Shen, G. L., and Yu R. Q. 2005. Modified ant colony optimization algorithm for variable selection in QSAR modeling: QSAR studies of cyclooxygenase inhibitors. Journal of Chem. Inf. Model. Vol. 45, pp. 1024-1029.

Xiuxia Y., and Yi, Z. 2006. Study of shipboard power system intelligent network reconfiguration. Proceedings of the Sixth International Conference on Intelligent Systems Design and Applications.

Yu Q., Solanki, J., Padmati, K., Kumar, N., Srivastava, A., Bastos, J.L., and Schulz, N. N. 2008. Intelligent methods for reconfiguration of terrestrial and shipboard power systems. IEEE Power and Energy Society General Meeting, Tampa, FL, USA.

\section{Biographical notes:}

Sri Hari Krishna Vuppalapati is currently pursuing his B.Tech final year in Electrical Engineering from Indian Institute of Technology, Kharagpur, West Bengal, India. He has done research projects as summer internship at Mississippi State University, Mississippi State, USA in 2009. His research interests include applications of optimization techniques to electrical engineering problems and power system reconfiguration.

Dr. Anurag K. Srivastava received his Ph.D. degree from Illinois Institute of Technology (IIT), Chicago, in 2005, M. Tech. from Institute of Technology, India in 1999 and B. Tech. in Electrical Engineering from Harcourt Butler Technological Institute, India in 1997. He is working as Assistant Research Professor at Mississippi State University since September 2005. Before that, he worked as research assistant and teaching assistant at IIT, Chicago, USA and as Senior Research Associate at Electrical Engineering Department at the Indian Institute of Technology, Kanpur, India as well as Research Fellow at Asian Institute of Technology, Bangkok, Thailand. His research interest includes power system security, power system modeling and real time simulation, electricity market and artificial intelligent application in power system. Dr. Srivastava is member of IEEE, IET, IEEE power and energy society, Sigma Xi, ASEE and Eta Kappa Nu. He serves as vice-chair of power engineering career promotion subcommittee and secretary of student activities subcommittee within IEEE power and energy society. He is recipient of several awards and serves as reviewer for several international journals and conferences.

Received December 2009

Accepted March 2010

Final acceptance in revised form March 2010 